\title{
Southern Ocean deep-sea biodiversity: sampling strategies and predicting responses to climate change
}

\author{
Stefanie Kaiser ${ }^{1,3, *}$, David K. A. Barnes ${ }^{2}$ \\ ${ }^{1}$ Zoological Museum, University of Hamburg, Martin-Luther-King-Platz 3, 20146 Hamburg, Germany \\ ${ }^{2}$ British Antarctic Survey, High Cross, Madingley Road, Cambridge CB3 0ET, UK \\ ${ }^{3}$ Present address: British Antarctic Survey, High Cross, Madingley Road, Cambridge CB3 0ET, UK
}

\begin{abstract}
The deep sea surrounds Antarctica and constitutes about $80 \%$ of the Southern Ocean (SO) seabed. Scientific cruises (e.g. ANDEEP) reveal that SO abyssal life can be highly abundant, rich and endemic. With a vast water volume, the buffering effect of ice, data paucity and low sampling effort, signals of regional change may not be detected there for some time. The deep sea is likely to change in many ways, particularly becoming more acid and warmer, but over centuries or millennia. More immediate is the possibility of abrupt change in the thermohaline circulation driven by massive surface freshening from glacial melt-water. This could strongly stratify the water column, decrease ocean overturning and the flow of oxygen to the global deep sea. Impacts on abyssal biota will be hard to detect because we know so little about it. The most important first step is to generate a baseline of abyssal biodiversity and key factors generating and maintaining it. Recent work has shown abundance of a model taxon varied similarly in samples 1000s, 100s and 10s of kilometres apart. Most taxa were extremely patchy, and new sampling is needed to reveal patch size, spacing and importantly what structures abyssal patches. We examined the 'big picture' where factors at scales of less than kilometres may drive variability. The understanding of these patterns should make estimates of deep-sea biodiversity meaningful and give a baseline indicating the scale, taxon and environmental feature to look at in order to detect the inevitable signal of climate change in this huge, remote environment.
\end{abstract}

KEY WORDS: Antarctic $\cdot$ Abyssal $\cdot$ Regional warming $\cdot$ Scale $\cdot$ Patchiness $\cdot$ Macrobenthos $\cdot$ Isopoda

\section{INTRODUCTION}

Recent analyses of ice cores taken from Canadian islands, Greenland and Antarctica have provided an exceptionally detailed view of how climate has varied over 8 glacial cycles (EPICA 2004). Carbon dioxide $\left(\mathrm{CO}_{2}\right)$, methane $\left(\mathrm{CH}_{4}\right)$ and temperature (amongst other things) have varied considerably, from peaks during interglacial periods to troughs during glacial maxima (ice ages). The concentration of $\mathrm{CO}_{2}$ is presently higher than at any time in the last 800 thousand years (kyr) and is rising at an unprecedented rate (Raupach et al. 2007). Temperatures have been higher before (for example in the last interglacial period), but their cur- rent rate of increase is unparalleled (Raupach et al. 2007). The rate of change is geographically highly patchy, and at its most intense in parts of the Arctic and West Antarctic regions (Hansen et al. 2006). It is hard to assess whether some physical changes, and biological responses to these, are (indirectly or directly) anthropogenically mediated or natural recovery from the last glacial maximum (LGM). Organisms have already shown a wide variety of responses to climate change, e.g., in phenology, range shifts and mortality (Walther et al. 2002). Another major feature associated with regional warming is the increased possibility of transport and establishment of some non-indigenous species (NIS) (Barnes et al. 2006). Most evidence of 
past and current response to climate change is from terrestrial organisms and habitats, rather than those in the sea. However, of the marine studies known to the authors, all have been carried out on shallow water organisms (Clarke et al. 2007). Very little is known about how the deep sea may be influenced by regional warming and potential impacts on population and community dynamics (Danovaro et al. 2004). This is mainly because sampling abyssal and hadal depths is technically difficult, time consuming and expensive, and, resultantly, little effort has been put into longterm surveys (Danovaro et al. 2004).

Most $(\sim 77 \%)$ of the world's ocean is deeper than $3000 \mathrm{~m}$, and therefore the deep sea constitutes by far the largest habitat type on earth. Likewise, in the Southern Ocean (SO), it dominates $(78.2 \%)$ the seafloor (Fig. 1), and as ice shelves cover much of the Antarctic continental shelf, we calculate that it comprises $82.2 \%$ of the seabed underlying open ocean (and therefore potential surface productivity). This environment must contain a significant (though little known) proportion of the planet's biota. Educated guesses made by researchers have suggested that there may be 10 to 100 million macrofaunal species

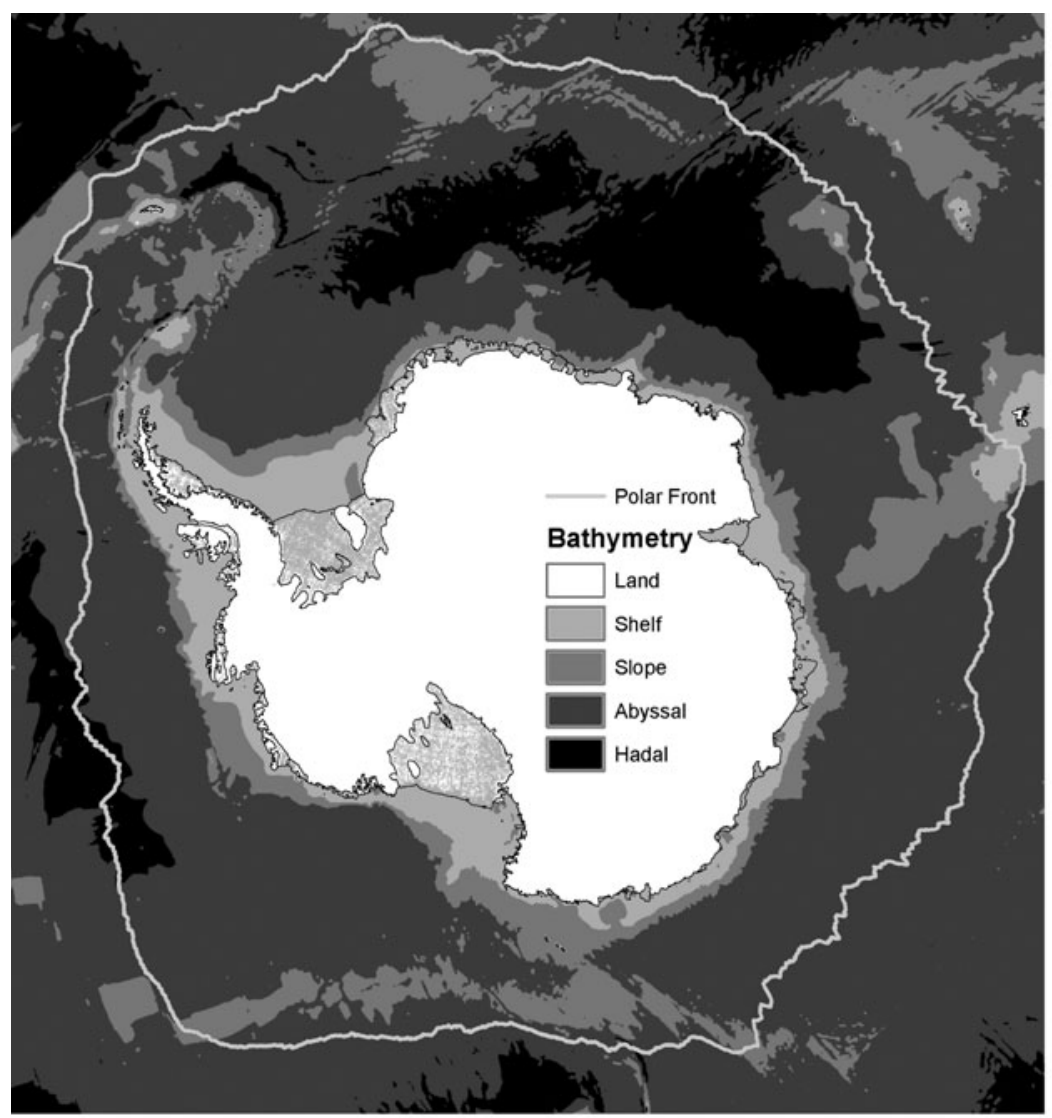

Fig. 1. Bathymetry of the Southern Ocean, showing shelf, slope, abyssal and hadal regions alone in the deep sea (May 1988, Grassle \& Maciolek 1992). Poorly sampled everywhere, data are especially rare for these species around Antarctica. In the present paper, the deep sea is defined (mainly in a SO context) as that below $3000 \mathrm{~m}$, following Clarke \& Johnston (2003). Around Antarctica the shelf and slope (and as a consequence, definitions of the deep sea) are all depressed, due to the weight of the massive ice sheet. The deep sea is characterised as much by these special conditions, as merely by depth (or pressure caused by depth).

A key feature of the deep sea is the constancy in certain environmental characteristics over geological time scales; this gives context to predicted future changes. Long-term constant physico-chemical parameters include temperature, salinity, oxygen and hydrostatical pressure, though there is evidence from fossil records from the North Atlantic of sudden changes in water circulation (Smith et al. 1997). Oceanic oxygen levels have varied considerably, but increased (doubled) over 200 million years (Falkowski et al. 2005). However, oxygen levels in the deep sea have fluctuated between more extreme conditions. Late Jurassic and Palaeocene anoxic conditions in the deep sea led to mass extinctions (e.g. Hallam \& Wignall 1997) and to subsequent recolonisation events (see e.g. Raupach et al. 2004). Oxygen has been, and is, transported to the deep sea from the polar regions. Water masses flowing through the world's deep ocean basins (below $4000 \mathrm{~m}$ ) mainly originate in the Antarctic (Jacobs 2004). Antarctic Bottom Water (AABW) generated partly in the Weddell and Ross Seas (linked to sea ice formation) spreads northwards, transporting high levels of dissolved $\mathrm{O}_{2}\left(\sim 10 \mathrm{mg} \mathrm{l}^{-1}\right)$ to the abyssal plains. The SO deep sea, thus, plays a major role in the global circulation system, and any change could strongly influence deep-sea areas worldwide.

Because of the complexity, cyclical nature and variable stability of ice, the $\mathrm{SO}$ is a difficult region for which to predict influences of warming. Furthermore, water mass and current paths are complex geographically, bathymetrically and seasonally. Even one of the strongest and most recognizable features, the polar front (PF) meanders over 100s of kilometres in ecological time and even further in evolutionary time (see Moore et al. 1999). Although sampling of biota in the Antarctic began 
$>120$ yr ago, samples taken in this decade in the best known Antarctic region, the Weddell Sea, still mainly comprise species new to science (see Brandt et al. 2007a). A variety of recent oceanographic and biological scientific cruises have made substantial progress, and warming signals have been detected as deep as $2000 \mathrm{~m}$, but not changes that are considered biologically significant (Gille 2002, Smedsrud 2005). Organisms in the deep sea are not disturbed by ice scour, and some are very long lived. Thus, skeletons of some foraminifera, corals and shelled taxa can potentially provide an important record over the last century or more. Longer time scales can be probed by investigation of deep sediment cores, which can reveal important clues about near bottom conditions over 10s or maybe 100s of 1000s of years (Petit et al. 1999).

In the present paper, we make one of the first attempts to evaluate how predicted regional warming may influence the deep SO benthos. This is particularly difficult, not just because the deep sea is so poorly known, but also because it is far from significant current warming signals. To date, most of the direct and indirect influences of climate change have only been measured at or close to the ocean surface or on land (e.g. Meredith \& King 2005, Turner et al. 2005). Furthermore, hard evidence for rapid recent increases in temperatures and ice retreat within the SO is restricted to the western Antarctic Peninsula (WAP) and the Scotia arc region. Thus, to date, there is no strong reason to suggest that much of the deep sea surrounding Antarctica is likely to be influenced by many aspects of climate change in the short term. Much of the present paper is an assessment of progress that has been, and needs to be, made towards knowledge and understanding of SO deep-sea benthos and the influences on it. Despite the fact that the deep SO is the least known environment around Antarctica and an area from which no signal of climate change has been detected, we argue that it could be the most important Antarctic biome. Acidity, freshening and warming, as a result of climate change, are already penetrating deeper water masses in some areas and are predicted to do so across the planet. Therefore, we consider the deep-sea environment and what changes are likely to occur at certain time scales. Most of what we know about SO biota so far concerns initial assessments of biodiversity, and investigating change in taxonomic richness, abundance and composition probably represents our best chance for detecting response. Impacts on the deep SO seabed are likely to indicate future changes to global deep-sea floor, our planet's largest environment. It may become an important area for continental shelf and slope organisms to escape shallower changes and must be the least anthropogenically impacted region on the planet.

\section{THE DEEP-SEA ENVIRONMENT OF THE SOUTHERN OCEAN}

The shelf and slope environments in the SO have distinct breaks such that they are isolated from those to the north by 100 s or 1000 s of kilometres of deep sea in between. In contrast, below $3000 \mathrm{~m}$ the SO deep sea is linked to all other ocean basins. Besides many hydrographical similarities to other deep-sea areas (e.g. hydrostatic pressure, temperature and salinity), the SO deep sea has some unique features. The calcite compensation depth (CCD) is much shallower than elsewhere and, in places, occurs as shallow as the shelf. Saturation levels of calcium carbonate $\left(\mathrm{CaCO}_{3}\right)$ are low, particularly of the aragonite form, and thus it is more difficult for biota with shells and skeletons to make and maintain them. Another unusual feature is the high level of mixing and connectivity with upper water masses. The SO deep sea is closely linked to the Antarctic shelf environment due to, e.g. primary production or the formation of AABW providing oxygen for deep-sea organisms. Bottom water masses generated in the SO comprise $50 \%$ of the volume of the world's ocean (Godfrey \& Rintoul 1998). As a result, the SO plays an important role in the regulation of the atmospheric $\mathrm{CO}_{2}$ budget, heat distribution and, thus, global climate (Petit et al. 1999).

The modern SO is characterised by low nutrient utilisation in the water column, lack of vertical zonation and intensive vertical mixing, which enhances the release of $\mathrm{CO}_{2}$ from the deep water back to the atmosphere (Francois et al. 1997). During the LGM the SO contributed significantly to the lowering of atmospheric $\mathrm{CO}_{2}$ due to less vertical mixing, removal of nutrients from the water column and higher sinking fluxes of organic matter to the deep sea (Watson \& Naveira Garabato 2006). Currently, the fastest changing areas are parts of the polar regions, and climate-generated factors altering the Antarctic shelf regions may very likely influence life in the abyss as well. During the last interglacial, the SO climate changed earlier than that of the North Atlantic (Kim et al. 1998), and thus the SO deep sea may be the first area where water current changes and variations in the thermohaline circulation (THC) will take place. We consider that the SO deep sea represents an early global warning system of abyssal response to climate change. Apart from studying recent impacts of regional warming on abyssal communities, the deep sea is, due to its exceptionally stable physical conditions (in terms of temperature and salinity), an ideal place to detect signals of past global changes (Lear et al. 2000). 


\subsection{Ecology}

Primary production can be patchily high, is typically dominated by diatoms, whereas coccolithophores are absent (due to the low temperatures) and, hence, biogenic oozes are almost exclusively siliceous in the SO deep sea (Clarke 1996). High nutrient concentrations in the water column show that these are not biologically efficiently used-most parts of the primary production bloom sink to the bottom (Anderson et al. 2002). Generally, deep-sea areas are characterised by a low energy input, depending on the overlying primary productivity. The latter is seasonal, and thus energy input is quite patchy in time and space, even more in the polar regions where more material sinks to the bottom due to decoupling from secondary production (Gray 2001). Deep-sea organisms show adaptations to these conditions of irregular food supply by adjusted reproductive (e.g. isopods; see Harrison 1988) or feeding modes to sustain long periods of no food supply such as in the scavenging amphipod Eurythenes gryllus (Hargrave 1985). The few studies on reproduction strategies of benthic deep-sea infauna (e.g. Blake \& Narayanaswamy 2004) have found that most of the model species show either direct development, lecithotrophy, or brooding.

\subsection{Biodiversity}

'Biodiversity is ... a comparative science' (Magurran 2004, p. 12), but comparisons between deep SO and other data are difficult, as samples are scarce and often collected with differences in sampling apparatus or protocol, bathymetric variability (Arntz et al. 1997), or size of the sample area (Gray 2001). Although popular, comparison of samples from a vast area such as the $\mathrm{SO}$ deep sea with smaller areas such as the Arctic probably has little value (see Gray 2001). Increasingly, it is becoming apparent that the SO deep sea is, within some taxa, remarkably rich and that species previously unknown to science comprise much of this richness. Apart from some species lists per sample, though, we know little more about SO abyssal ecology. Although there have now been several scientific cruises collecting abyssal mega- and macrobenthos, to date there is still no published report of higher taxon richness in trawls for any SO region or even site. Malyutina (2004) gave a general overview of higher taxon richness from several Russian SO deep-sea expeditions, but use of differing types of trawls makes their data difficult for comparison. Richness has been quantitatively assessed at a decimetre scale. In total, >21 phyla and 30 classes have now been reported from the SO deep sea (Table 1). Gutzmann et al. (2004) reported 10 phyla of meio- and macrofauna from their multicorer (MUC) samples. This suggests considerable higher taxon richness, as this is nearly half the total phyla that have ever been recorded there. However, scaling-up values from $<1 \mathrm{~m}$ of seabed sampled to even 10 to $100 \mathrm{~km}$ scales would be unlikely to be meaningful due to sampling bias (of MUC) and patchy or rare distributions.

Richness may not be well known at higher levels, but also very few groups have been studied in any detail at generic or species levels in the SO abyss. Despite such little sampling effort at this level, species known from SO abyssal depths already comprise a significant fraction of the total SO fauna in many taxa (Fig. 2). Less is probably known about lower taxon richness of the deep SO benthos than for any other area of the planet. Of course, as with higher taxonomic levels, this is partly due to low sampling effort, but also some groups have been much better studied (e.g. Isopoda) than others. Some taxa are probably often overlooked or undersampled due to their small size and low densities (such as the Halacaroidea; Gutzmann et al. 2004) or cryptic habits and taxonomic difficulties (such as Nemertea; Rogers et al. 1998). Unlike, for example, the isopods, other groups are less well known partly because there does not happen to be a currently active community of taxonomists studying current samples. Even more than on the SO shelf, abyssal research has been much more focussed in some regions (e.g. Weddell Sea) than others. Nevertheless, there have been a few quantitative studies comparing species richness across most taxa (e.g. Blake \& Narayanaswamy 2004). Work to date suggests some groups are proportionally rich (e.g. isopods and polychaetes; see Brandt et al. 2007a,b), whilst some others are comparatively poor, such as the gastropod molluscs (e.g. Schwabe et al. 2007) and many suspension feeders. The last few decades have revealed that species richness of many shelf taxa in warm and even polar waters have been underestimated due to previously undetected cryptic speciation. For example, haplotypes of the widely distributed isopod Acanthaspidia drygalski, otherwise morphologically similar, have now been genetically distinguished (Raupach \& Wägele 2006).

The difference between higher and lower taxonomic levels is most obviously seen in endemism. At family and higher levels, SO deep-sea endemism is virtually zero, at generic levels it is low (similar to other ocean basins; Clarke 2003), but at the species level may be quite high in some taxa (Brandt et al. 2007b). More comprehensive sampling may reduce the apparently very high endemism in deep-sea organisms as is happening on the shelf (Barnes \& Peck 2008, this Special). Many SO deep species are known from just a single sample (Brandt et al. 2007a, their supplementary material). So the level of study in the SO abyss to date 
Table 1. Meio-, macro- and megabenthic (invertebrate) taxa known from the Southern Ocean (SO) deep sea compared to total SO richness. Species richness data are from the literature or personal communication and usually refer to described species. The deep sea is defined here as areas below $3000 \mathrm{~m}$, following Clarke \& Johnston (2003); only data from Brandt et al. (2007b) refer to deep sea as areas below $1000 \mathrm{~m}$. The system of classification follows Barnes (1998). Other phyla (and classes) present in the deep SO are: Cnidaria (Anthozoa, Hydrozoa), Acanthocephala, Platyhelminthes (Trematoda, Monogenea, Cestoda), Nemertea, Gastrotricha, Kinorhyncha, Loricifera, Rotifera, Mollusca (Polyplacophora), Echiura (Echiurida), Priapula (Priapulida), Sipuncula (Sipunculida), Crustacea (Cirripedia, Tantulocarida, Copepoda), Tardigrada, Chelicerata (Arachnida), Echinodermata (Stelleroidea, Ophiuroidea, Holothuroidea) and Chordata (Ascidiacea) (after Rogers et al. 1998, Walter et al. 2002, Gutzmann et al. 2004, Malyutina 2004, Gili et al. 2005)

\begin{tabular}{|llccl|}
\hline Phylum & Class & $\begin{array}{c}\text { No. of SO } \\
\text { deep-sea species } \\
\text { and (total no.) }\end{array}$ & $\begin{array}{c}\text { Percent of } \\
\text { total SO } \\
\text { species }\end{array}$ & \\
\hline Porifera & Hexactinellida & $45^{\mathrm{a}}(50)$ & 90.0 & Brandt et al. (2007a,b) \\
& Demospongiae & $100^{\mathrm{a}}(400)$ & 25.0 & \\
Nematoda & $15^{\mathrm{a}}(20)$ & 75.0 & \\
Bryozoa & Gymnolaemata & $22(1899)$ & 1.2 & Vanreusel \& Vincx (2003), P. Martinez Arbizu pers. comm. \\
Brachiopoda & $1(393)$ & 0.3 & Hayward (1981), Barnes \& Griffiths (2008) \\
Chelicerata & Pycnogonida & $40(275)$ & 15.6 & Clarke \& Johnston (2003), Munilla (2008) \\
Crustacea & Amphipoda & $84^{\mathrm{a}}(510)$ & 16.5 & Brandt et al. (2007a) \\
& Isopoda & $55(371)$ & 14.8 & Schotte et al. (1995 onwards), Brandt et al. (2007a) \\
& Tanaidacea & $16(127)$ & 12.6 & Brandt et al. (2007b), Guerrero-Kommritz pers. comm. \\
& Ostracoda & $\sim 60(\sim 270)$ & 22.2 & S. N. Brandao pers. comm. \\
Annelida & Polychaeta & $\sim 250(645)$ & 38.8 & Clarke \& Johnston (2003), Schüller \& Ebbe (2007) \\
Mollusca & Bivalvia & $42(161)$ & 26.1 & Griffiths et al. (2003), Linse et al. (2006) \\
& Gastropoda & $49(566)$ & 8.7 & Griffiths et al. (2003), Linse et al. (2006), Brandt et al. (2007b) \\
& Scaphopoda & $6^{\mathrm{a}}(8)$ & 75.0 & Brandt et al. (2007b) \\
& Cephalopoda & $3(56)$ & 5.4 & Collins \& Rodhouse (2006), J. Guerrero-Kommritz pers. comm. \\
Echinodermata & Asteroidea & $18(131)$ & 13.7 & E. Mutschke pers. comm. \\
& Echinoidea & $16^{\mathrm{a}}(74)$ & 21.6 & Brandt et al. (2007b) \\
a Areas below & & & \\
\hline
\end{tabular}

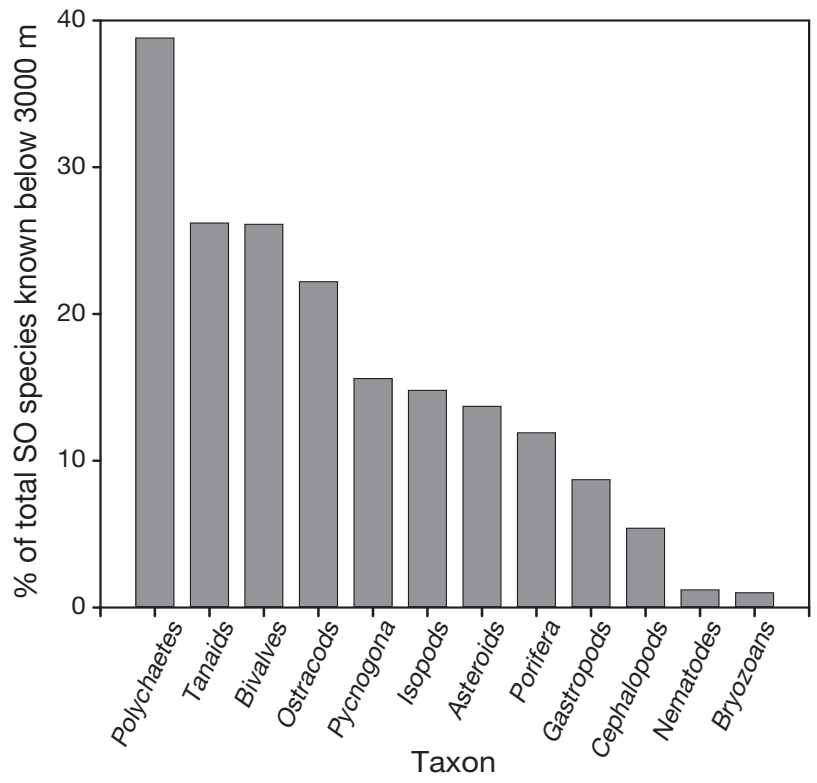

Fig. 2. Proportion of species of different taxa known from abyssal depths compared to total number of Southern Ocean (SO) species (using data from Hayward 1981, Schotte et al. 1995, Griffiths et al. 2003, Vanreusel \& Vincx 2003, Collins \& Rodhouse 2006, Linse et al. 2006, Brandt et al. 2007b, Schüller \& Ebbe 2007, P. Martinez Arbizu pers. comm., J. GuerreroKommritz pers. comm., S. N. Brandao pers. comm.) is such that calculation of species endemism levels either by region or even for the SO is relatively meaningless. However, it is clear that many endemics otherwise known from the continental shelf and slope also occur in the deep sea (e.g. Brandt et al. 2007b). Whilst the shelf is not continuous anywhere between Antarctica and other areas, the deep sea is, and the PF probably represents much less of an oceanographic boundary given that Antarctic bottom water flows into the deep sea of other oceans. Thus, an alternative hypothesis could be that endemism of the deep SO is much lower than that of shelf fauna. Due to the low sampling effort and sampling size per area so far, and a lack of comparable data of adjacent ocean basins, almost nothing is known about species ranges. Due to the relatively deep shelf, the lack of thermocline and the presence of many eurybathic species, there is no strong oceanographic or faunistic zonation apparent similar to that described from temperate deep-sea regions (Brandt et al. 2007b). With respect to looking for and at signals of climate change, investigation of change in ranges (geographic and bathymetric) will be an important target for future expeditions.

Although paucity of samples has made them largely points of debate, some initial investigations have been 
made into possible trends in deep-sea biodiversity. A gradient of increasing diversity from the shallows to the deep sea has been suggested (Grassle \& Maciolek 1992). However, the area they sampled was small for any larger scale generalised statements about patterns (Gage 2004, Kaiser et al. 2007). Is a comparison of shelf and deep-sea diversity meaningful? Gage (1996) suggested that the first comprises many different habitats and the latter is possibly just 1 homogenous area; thus, in his view, $\beta$ is being compared with $\alpha$-diversity. Considerations have to be made as to whether the deep sea really does just represent 1 habitat and whether shelf vs. deep sea comparisons are valid. It is likely that many factors, e.g. sediment, varied along the $176 \mathrm{~km}$ transect that Grassle \& Maciolek (1992) sampled (Gray 2001). ANDEEP samples revealed several habitats in terms of different sediment types and origin (e.g. volcanic, terrigenous, biogenic; see Vanhove et al. 2004), and areas of bottom water production and increased surface productivity (e.g. Howe et al. 2004). Comparisons of species richness per area yielded no depth trend between shelf and the deep sea (Gray 2001) or within the SO deep sea (Brandt et al. 2007a).

Appreciation of abundance or density is also important for assessment of diversity. The density in Gutzmann et al.'s (2004) samples showed a negative correlation and, hence, a decrease in abundance of higher taxa with increasing depth. Patterns in overall faunal abundance have been described as very unevenly distributed, mainly driven by trends in nematodes (Gutzmann et al. 2004). Some taxa, amongst the betterknown macro- and megafauna, are very abundant as well as rich (e.g. peracarid crustaceans and polychaetes). In contrast, other groups are clearly rare, such as the bryozoans or decapod crustaceans (Brandt et al. 2007b; Table 1). Considering how few studies and little area has been sampled, a provisional conclusion must be that the SO deep sea is very rich at higher taxonomic levels, but, to determine how evenly this is spread, too little is known to compare diversity with other areas.

The extended depth of the SO continental shelf and the lack of thermocline should make any transition of the fauna from the Antarctic shelf to the deep sea (or vice versa) less challenging than elsewhere (e.g. Brandt et al. 2007a). Some taxa there show high levels of eurybathy (e.g. Schotte et al. 1995, Munilla 2008; Fig. 3). The level of eurybathy in polychaetes does not seem to differ between polar and temperate regions, but the depth of the transition from shelf to deep-sea fauna is deeper (Brandt et al. 2007a). Physiologically, polychaetes seem to be well adapted to changes in temperature and hydrostatical pressure, which makes emergent and submergent migrations potentially easier in this group (Hilbig et al. 2006). Whilst species endemic to the abyss reproduce there, those with a wider distribution probably reproduce primarily on the shallow slope (Blake \& Narayanaswamy 2004).

\section{CLIMATE CHANGE AND POSSIBLE RESPONSES}

On average, the surface of our planet has warmed by about $0.6^{\circ} \mathrm{C}$ over the last century, but this warming is geographically very uneven (Hansen et al. 2006). Some areas, notably East Antarctica, have shown no trend or even slight cooling, most areas appear to be warming and parts of the Arctic and the WAP are warming very rapidly (nearly $0.6^{\circ} \mathrm{C}$ decade $^{-1}$ ). Air temperatures (Turner et al. 2005) and, more recently, sea temperatures (Meredith \& King 2005) around the central and northern WAP have been consistently increasing since the 1950s. There are strong signs of regional responses to such warming, such as a decrease in seasonal sea ice (Zwally et al. 2002) and the fact that most glaciers are retreating or doing so at an increasing rate (Cook et al. 2005). There have also been regional biological responses to elevated temperatures and associated melting, but to date these have only been demonstrable on land (Walther et al. 2002).

Sea temperatures south of the PF (here defined as the $\mathrm{SO}$ ), cooled to current levels several million years

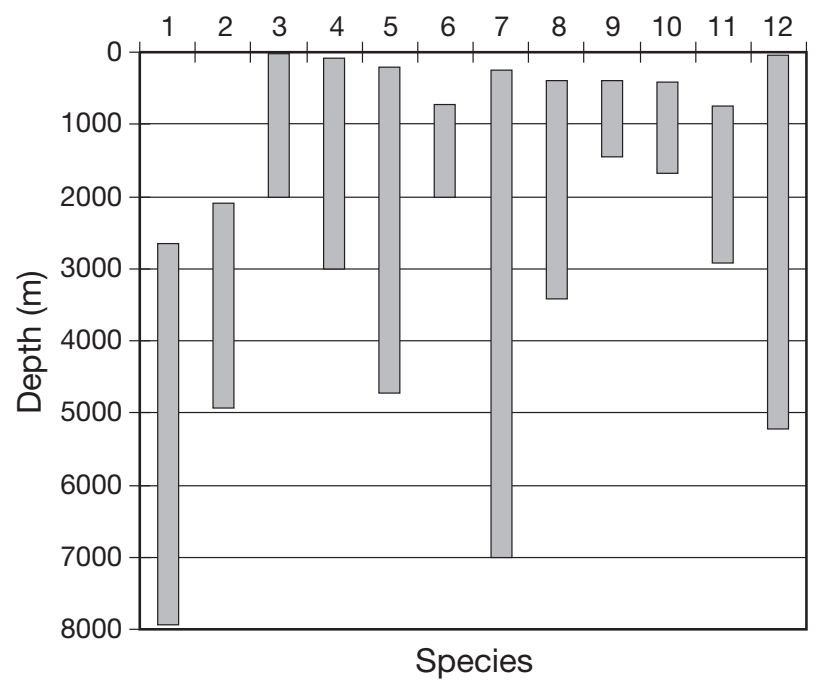

Fig. 3. Eurybathy in selected species of isopod crustaceans: (1) Disconectes vanhoeffeni (2659 to $7934 \mathrm{~m})$, (2) Disparella maiuscula (2086 to $4931 \mathrm{~m})$, (3) Dolichiscus meridionalis (24 to $2000 \mathrm{~m}$ ), (4) Antarcturus furcatus latispinis (75 to $3000 \mathrm{~m}$ ), (5) Eugerdella serrata (200 to $4720 \mathrm{~m})$, (6) Acanthaspidia longiramosa (720 to $2016 \mathrm{~m})$, (7) Ilyarachna antarctica (252 to $7000 \mathrm{~m}),(8)$ Munnopsurus australis (400 to $3423 \mathrm{~m})$, (9) Vanhoeffenura robustissima (400 to $1455 \mathrm{~m}$ ), (10) Vanhoeffenura spinossisima (417 to $1581 \mathrm{~m}),(11)$ Serolis antarctica (738 to $2925 \mathrm{~m}$ ), (12) Leptanthura antarctica (50 to $5216 \mathrm{~m}$ ). After Schotte et al. (1995), A. Brandt (unpubl. data) and S. Kaiser (unpubl. data) 
ago and, since then, have varied very little (Zachos et al. 2001). Only west of the Antarctic Peninsula (AP) have sea temperature increases been reported as both significant and biologically meaningful (Meredith \& King 2005). To date, warming trends detected below $50 \mathrm{~m}$ anywhere in the SO are currently only fractions of a degree across multiple decades. Despite this, the tripling of the rate of increase of $\mathrm{CO}_{2}$ aerial emissions in the last decade (Raupach et al. 2007) suggests future intensification of warming, given the strong link between concentrations of the gas and past temperatures (Raupach et al. 2007).

\subsection{How might the abyssal region change?}

It is, of course, not straightforward to predict how abyssal regions might respond to current and future climate change. Evidence from past changes is scarce or distributed patchily across the literature, and most studies are based on models that show very contradictory results, e.g., with respect to the stability of the THC (Rahmsdorf 2000) or the sequestration of $\mathrm{CO}_{2}$ in the deep sea (Hoppema 2004). Hoppema (2004) found that the Antarctic Central Intermediate Water (CIW) is a very effective water mass for transporting $\mathrm{CO}_{2}$ to the deep sea $(6 \%$ of global carbon export compared to $0.4 \%$ surface area of CIW). The saturation levels of $\mathrm{CaCO}_{3}$ are low in the $\mathrm{SO}$ and seem likely to decrease with increasing acidity, so it will become harder for organisms to synthesise and maintain shells (Orr et al. 2005). Transport of $\mathrm{CO}_{2}$ to the deep sea, however, seems to be very sensitive to surface layer changes, such as during glacial-interglacial transitions. During at least some glacial times the flow of CIW was reduced, increasing atmospheric $\mathrm{CO}_{2}$ partial pressure (Hoppema 2004). Such an increase is contrary, though, to the general lowering of $\mathrm{CO}_{2}$ during glacial periods (see Francois et al. 1997, Anderson et al. 2002). However, the coupling between the abyss and adjacent shelf areas and atmosphere and its relative constancy in ecological time makes signals of change likely and easier to detect. Surface changes influencing deep-sea communities should be particularly strong in the SO because of the seasonally strong mixing and bottom water being formed from sinking surface water. Significant surface warming has already been detected in the Bellingshausen Sea (Meredith \& King 2005), and thus we suggest that it is likely already happening in some surface areas of bottom water production. It is possible that change has not been detected around the Weddell or Ross Sea surfaces, because any warming is continually being transferred to the abyss by downwelling. If this is the case, it may prove hard to initially detect because of conduction and thus dilution of the effect. Studies on the timing and magnitude of past climate change often use proxy records from deep-sea sediments due to their high levels of constancy compared to surface water (Lear et al. 2000), and deep-sea cores reveal a high-resolution picture of our atmospheric and climatic past (Petit et al. 1999). Yet, timing when changes will become apparent in the deep sea is afflicted with high uncertainties, due to the buffering effect of this huge water mass. Future changes are likely to include changes in the ventilation as reported for the North Atlantic using deep-sea corals as a proxy (Adkins et al. 1998), but can also be seen by looking at benthic foraminifers in deep SO sediments (Ninnemann \& Charles 2002). There is a balance between North Atlantic Deep Water (NADW) and SO deep water formation, and changes in the outflow of Antarctic deep water will probably alter the formation of NADW and vice versa (e.g. Kim et al. 1998, Ninnemann \& Charles 2002).

It is conceivable that near future warming will result in major freshening around West Antarctica as has been reported in the North Atlantic and Ross Sea (Jacobs et al. 2002). A recent coupled global climate model projected significant decrease of sinking rates and so deep-sea ventilation (Richardson et al. 2005). Predicted abrupt (even on the scale of decades) slowing of the THC is known from the past in the North Atlantic (Dickson et al. 2002). Modifications of these huge water masses may affect benthic communities on a global scale due to, e.g., altering $\mathrm{O}_{2}$ distribution. In surface waters it seems likely that $\mathrm{O}_{2}$ depletion will occur earliest in the tropics (where levels are lower and there is less mixing), but, in the deep sea, we suggest that the earliest signs will be at high polar latitudes. If oceanic overturning gradually or even abruptly slows, the transport of $\mathrm{O}_{2}$ to the deep sea will be drastically reduced in the polar deep sea and, thus, to the global deep sea. We consider it is as important to look at localscale changes of near-bottom currents, as these are suggested to be critical factors with respect to community structure and composition through altering sediment mobility and, thus, its characteristics (Levin et al. 2001).

A significant warming of the Antarctic Circumpolar Current (ACC; Gille 2002) and Weddell Sea Deep Water (WDW; Smedsrud 2005) has been measured over several decades, and the temperature increase is faster than that of the global ocean (Gille 2002). To date, this warming has not directly influenced deepsea organisms, as it has been detected at mid-water depths (down to $2000 \mathrm{~m}$; Smedsrud 2005). There appears to be some cyclical cooling and warming in the WDW, so that the current warming might be not directly connected to regional warming, but to local variations (Smedsrud 2005). However, recent models 
do project significant abyssal water warming in response to surface freshening, in turn, driven by regional warming, but at levels insignificant to biota $\left(0.05^{\circ} \mathrm{C}\right.$; see Richardson et al. 2005). Evidence from the past has revealed a connection between global warming and deep-sea temperatures. Kennett \& Stott (1991) suggested a benthic mass extinction in Antarctic waters at the end of the Palaeocene-Eocene Thermal Maximum (PEMT) caused by considerable changes in ocean circulation, warming of the deep sea and, thus, a decrease of oxygen concentration. During this time, deep-water circulation slowed down and some persistent anoxic areas developed, and this may be a nearfuture scenario for deep-sea environments.

In summary, we consider that initial effects on the deep-sea environment will be minor, involving increases in production and sedimentation. Of most consequence will be a gradual or, possibly, abrupt change in the $\mathrm{THC}$, leading to drastic current, heat flux and oxygenation shifts. Over longer time scales, temperature and acidification are projected to increase downwards with mainly physiological consequences. These are summarised in Table 2.

\subsection{Expected impact on SO biota}

Past and current work on response of Antarctic marine organisms to 'climate change' has entirely focussed on shallow shelf species and mainly on tolerance to raised temperatures (for a recent review see Peck 2005). It is now technically possible to collect deep-sea animals under pressure, such that similar temperature tolerance experiments could be performed on abyssal species, but this has not yet been undertaken to our knowledge. Early work that established SO shelf fish to be highly stenothermal has now been repeated across a wide range of taxa (Peck 2005).
Experimental physiology suggests that Antarctic animals cannot acclimate to slightly raised temperatures, because they cannot supply oxygen fast enough. However, even less severe temperature rises may hinder or prevent Antarctic animals from performing tasks such as predator avoidance (Peck 2005). This line of evidence suggests Antarctic organisms are under extreme threat from the warming component alone of predicted climate change. The extent to which such short-duration laboratory experiments represent true tolerances is, however, debated (see Barnes \& Peck 2008). The alternative to adaptation or tolerance of future temperature rises for Antarctic shelf animals is for them to migrate (geographically or bathymetrically) or become extinct. Tolerance may prove a possibility as most of Antarctica shows no warming trend yet and, if this situation persists, the shelf around East Antarctica and high latitudes of West Antarctica may remain cool. Furthermore, Antarctic shelf and deep-sea organisms are likely to have considerable scope for bathymetric migration (into cooler deeper waters) as they are thought to show high levels of eurybathy (Brey et al. 1996). In summary, the true ability of Antarctic shelf organisms to cope with direct warming is unknown, although it is suspected to be low (but debated), and their ability to migrate is reduced geographically, but extended bathymetrically.

Raised temperatures are, though, only one of many features of climate change to which animals are and will be exposed. The retreat of glaciers, for example, along the AP (see Cook et al. 2005) has opened up new areas for primary productivity, new habitat for benthos and freshening (from melt water) (Clarke et al. 2007). Each of these has potentially important and differing impacts on organisms. Of these, the most obvious change, which might impact the deep sea as well as the shelf areas, is surface freshening. Surface freshening can influence the water column and the seabed

Table 2. Main factors changing now and in the near future in the SO abyssal environment and their timing, magnitude and potential effects on biota. NIS: non-indigenous species; THC: thermohaline circulation

\begin{tabular}{|c|c|c|c|c|}
\hline Factor & Likely trend & Time scale & Effect magnitude & Possible effects \\
\hline Food supply & Increases: area \& duration & Now-10 yr & Local & Increased 2nd production \& diversity \\
\hline Sedimentation & Increases near slope & Now-10s of years & Local & Clogging \& burial of benthos \\
\hline $\begin{array}{l}\text { NIS } \\
\text { establishment }\end{array}$ & Arrival & Now -100 s of years & Regional & $\begin{array}{l}\text { Composition change, decreased } \\
\text { diversity }\end{array}$ \\
\hline THC & Gradual or abrupt slowing & Years-100s of years & Global & $\begin{array}{l}\text { Ecosystem change, increased } \\
\text { abundance, decreased diversity }\end{array}$ \\
\hline Oxygenation & Decreases & $10 s-100$ s of years & Global & Decreased survival of larger species \\
\hline Temperature & Increases from surface down & $10 \mathrm{~s}-100 \mathrm{~s}$ of years & Regional-global & $\begin{array}{l}\text { Downslope migration, stress to } \\
\text { stenotherms, invasion? }\end{array}$ \\
\hline Acidification & Increases from surface down & 100 s of years & Regional-global & $\begin{array}{l}\text { Reduced skeleton/shell synthesis, } \\
\text { increased predation }\end{array}$ \\
\hline
\end{tabular}


below it in many ways, most obviously by increasing stratification and thus decreasing water column penetration of light, oxygen and other factors. Some of these factors are likely to also be important to the deep sea, whilst others may be of negligible or have no direct impact on biodiversity there.

\subsection{Expected impact on deep SO biota}

Many of the influences of climate change on surface waters are projected to take considerable time, 100s of years to reach the abyss and thus influence the biota, but not all. These are summarised in Table 2. Initial influences on deep-sea biota are probably already happening through increased surface productivity due to ice shelf collapses and decreased marginal sea ice duration and extent. Similarly sedimentation is probably increasing as are the chances of localised downslope slumps resulting in the burial of communities. A rapid and massive shift towards freshening has been measured in parts of the North Atlantic, intensifying over the last few decades. The most important, likely ecosystem shifting, influence will be a slowing down of the THC prompted by massive inundation of the ocean surface by melt water. Wide-scale freshening of Arctic surface waters later spread to deep North Atlantic water masses (Dickson et al. 2002). These authors suggest this is of special concern, as in the past such changes have disrupted the THC and thus abruptly changed ocean heat and gas distributions. It seems likely that most of the influences expected will occur sooner and be more severe in shelf waters before influencing the deep sea. For example, acidification, warming and freshening all occur through surface interactions and penetrate the deep from there. However, $\mathrm{CaCO}_{3}$ saturation levels are much lower in the deep sea, so proportionally less acidification is needed to have a greater effect on biota. Furthermore, past constancy of acidity levels means that deep-sea organisms are less used to coping with rapid fluctuations in saturation levels. Present and projected changes are likely to be much more severe than even the drastic increase in acidity and thus decrease in $\mathrm{CaCO}_{3}$ saturation at the PEMT (55.5 to 54.8 million yr ago) (Zachos et al. 2005). The immediate effect of a drastic slow down in ocean overturning would be very apparent on the surface because of changes in heat distribution and thus abrupt changes in temperature. The mid- to long-term influence would be as much or more severe to the deep-sea environment though because of reduction in mixing and oxygen supply. Only at the polar regions is there strong connectivity between the deep sea and the surface; thus, a halt in ocean overturning would isolate the global deep sea and its biota.
Studies on Pacific foraminifers have revealed that oxygen minimum zones (OMZ) there expanded during interglacials and species typical of low oxygen concentrations dominated, whilst, during cool periods, species typical of higher oxygen concentrations were more abundant (see Levin 2002). Past OMZ expansion is considered a result of climate change, and computer models already suggest a great annual loss of oxygen from the world's oceans of which a high amount would be taken from the SO deep sea (Levin 2002). However, the loss of oxygen in the SO deep sea will probably be negligible and not physiologically significant for deepsea biota within the next $100 \mathrm{yr}$.

Ultimately, the collapse of ice shelves and a decrease of surface ice-loading provide more coastal surface area for primary production, but this may not necessarily increase food supply to the deep sea (Piepenburg \& Gutt 2006). Small changes in food web structure may be very noticeable, as weak interactions are important for the stability of a community (Clarke et al. 2007). Currently, inner-ice communities and ice-edge phytoplankton blooms are an important food source for deep-sea organisms, but, if the extent of seasonal ice continues to decrease and ice shelves retreat, these food sources will be reduced and maybe disappear. Elsewhere, $\mathrm{CO}_{2}$ injection programs have been developed over the last 3 decades (Thistle et al. 2007) to remove $\mathrm{CO}_{2}$ from the atmosphere and directly inject it into the deep sea. Consequential small-scale studies on the impact of this $\mathrm{CO}_{2}$-laden, acidic seawater on deep-sea benthos revealed high rates of meiofaunal mortality (Thistle et al. 2007).

It seems very likely that faunal shifts will occur in the deep sea, as is already happening in surface environments and as diatom and foraminifer evidence suggest has happened in the past (Lear et al. 2000). Yet, at the moment, we do not know the fauna well enough to detect shifts. There is much evidence that the present SO fauna is a combination of various submerging and emerging processes (Brandt et al. 2007b), and that these events were, are and will be an important feature of the SO past, present and future faunal composition. The high levels of eurybathy in many Antarctic species are thought to be adaptations to glacial-interglacial cycles, whereby eurybathic species were able to escape unfavourable conditions on the shelf by submergence (Brey et al. 1996). The vast volume and mixing of the SO should mean the abyss could again be a refuge, not from expanding ice shelves during glaciation, but from a thermal maximum without precedent in recent time.

Although marine NIS have been reported from the SO, no animals are known to have established yetthe only large area for which this is true. However, over the planet's entire surface, human activity has 
proved a very strong vector for NIS transport and establishment. The timing of intensification of regional warming is coincident with unparalleled anthropogenic transport to the region. Typically, this is likely to spread NIS between regions in the shallows, but similarity of conditions deeper or freak events may aid dispersal to the slope and abyss. If, for example, the tourist ship 'Explorer', which recently sank at slope depths near the South Shetland Islands, had NIS on its hull or in ballast water, as other ships in the region have been found to be carrying (Lewis et al. 2003), these would be delivered directly to the seabed. Yet, the knowledge of deep-sea fauna is so poor, in the SO as throughout the world, that NIS arrival and establishment there would be nearly impossible to detect.

Central to any considerations of how deep-sea biota may be impacted by climate change are the quality of data and the understanding of processes underpinning it. If investigation of aspects of biodiversity represents the best opportunities for detecting change in the SO deep sea, we must scrutinise how biodiversity is currently being measured and whether new approaches are needed.

\section{PREDICTING RESPONSES OF BIOTA TO CLIMATE CHANGE}

\subsection{Is biodiversity the best indicator for potential deep SO ecological change?}

On land and in the shallows of shelf waters a variety of approaches have been taken to assess vulnerability of polar fauna to present and projected climate change. A major component of such research involves laboratory or field manipulations of variables, such as acidity or temperature. Experimental approaches are extremely difficult for scientists to study biota that lives in the deep sea because of habitat inaccessibility or damage and stress to organisms removed from it. It is also true that aspects of biodiversity are the best studied of what little we do know about deep-sea biota. Levels of knowledge certainly make monitoring of changes in biodiversity an appropriate aspect for the assessment of deep-sea responses to climate change, but actually, at the current time, there are few other realistic alternatives. Physiological experiments of response to manipulated acidity, temperature, sedimentation and other factors could be investigated in species with bathymetric ranges spanning the shallows to the deep sea. Yet, this would involve major assumptions that the deep-sea populations of the same species might respond similarly. Alternatively, calcification levels of species that occur across a range of saturation levels of $\mathrm{CaCO}_{3}$ (with depth) could be examined, which would not necessarily require animal husbandry. However, it seems likely that most of our information about potential responses is going to come from comparative assessment of aspects of biodiversity. The main question is - which aspects? Most deep-sea data collected to date concern simple richness levels, in which change will tell us little. However, at least in the Weddell and Scotia Seas, sample density and levels of knowledge are higher, and new insights are being extracted from existing data (Kaiser et al. 2007). Elucidating the scale on which richness varies and what drives richness will be key steps forward.

Before we can assess possible organism responses to change, we must consider how the SO deep-sea environment will physically and chemically alter as a result of climate change. To date, climate models have not proved very successful at recreating actual data of present climate change, let alone projecting short-term and medium-term future trends. Part of the problem is the level of complexity and that most past data are from when the Earth was in greater balance compared with the very rapid multiple changes associated with human activity. Nevertheless, there is a suite of strongly expected physical oceanographic changes, including $\mathrm{pH}$ change and associated influences on carbonate saturation levels, temperature, freshening, circulation and oxygen content.

\subsection{Measuring SO deep-sea biodiversity}

Obtaining robust estimates of biodiversity is clearly important, but a mere list of taxa — species richness is clearly a poor descriptor and can vary drastically between apparatus, observer and many other parameters. Making measurements meaningful and comparable is a major challenge, especially in the deep $\mathrm{SO}$, with few, expensive scientific cruises run by scientists from different nations and taxonomic focus. Progressing from simple species lists, measurements of more value include how evenly species are spread in abundance or taxonomic similarity in an assemblage (Magurran 2004). As faunal pattern can vary considerably across spatial scales, even within a seeming homogeneous habitat (Ellingsen 2001), several samples within a habitat are critical to assess community variability (e.g. in species composition) and distribution patterns (Ellingsen 2001). Defining habitats or microhabitats, however, is not an easy task in the normally uniform deep sea. It is likely that measurement of deep SO diversity to date is between habitats ( $\beta$-diversity) rather than within a habitat ( $\alpha$-diversity). With new and more detailed techniques and especially the study of sediment origin, chemistry, granulometry, oxygenation, surface rugosity and organic content 
coupled with strong variation in bottom currents, it is becoming clear that SO deep-sea habitats can be highly varied (e.g. Howe et al. 2004, Brandt et al. 2007 a, their supplementary material).

Setting the 'right' scale to measure distributional and diversity patterns is inappropriate, as this depends on the species or animal type studied (e.g. Levin 1992). Ideally, diversity across a range of scales needs to be quantified, but when measured at small spatial scales data should not be extrapolated to a larger scale (Thrush \& Warwick 1997). In a first cross-scale survey on deep SO macrofauna, Kaiser et al. (2007, unpubl. data) found similarly high levels of variability (patchiness) in abundance and richness across 3 spatial scales (samples taken $10,10^{2}$ and $10^{3} \mathrm{~km}$ apart) and taxonomic levels (genus, family, order) studied. They concluded that the nature of patchiness (e.g. patch size, dynamics and distance between patches) needs to be explored on a smaller scale than has been measured to date. The importance of small-scale studies to measure deep-sea biodiversity has been shown by Jumars (1978), who assessed the vertical and horizontal distribution of deep-sea macrobenthos across different (horizontal and vertical) spatial scales $(0.01$ to $500 \mathrm{~m})$. Meso-scale studies will be valuable to elucidate the population structure of taxa, the development of communities and the importance of vertical dimension to segregation and partitioning (Jumars 1978).

The key to progress is how biodiversity should be measured to achieve highest resolution, greatest comparability and earliest signals of significant change. The type of sample apparatus seems to have been the first consideration for much past work. Central to the measurements of megabenthos have been Agassiz trawls and deep remotely operating vehicles (ROV). The macrobenthos has usually been sampled using epibenthic sledge (EBS) and box corer, whilst meiofauna measurements have used MUC. Quantifying richness and abundance is delicate using some of these types of apparatus (e.g. EBS), but quantitative apparatus such as MUC sample only tiny areas $\left(<1 \mathrm{~m}^{2}\right)$; devices like ROVs are only appropriate for larger epibenthos, as photographs do not reveal cryptic fauna. Perhaps of most importance, though, is sample design, in terms of sample area, replication and distances between replicates versus sites (Fig. 4). It will be important for consensus to be reached amongst research teams, to standardise protocols and to collect more habitat information than has been practice to date. Samples are often split into component taxa and sent to specialists with no future communication or oversight of overall or comparative patterns. Sampling homogeneity across research teams would be significant progress, but simultaneously, data interpretation must be considered.
In terms of analysis, the best practice would be to compare richness and diversity between areas when taxon accumulation curves reach their asymptotes; however, few if any areas in the SO deep sea have been sampled to this degree. A variety of diversity indices are currently used. Many indices are sensitive to sample size (such as the Shannon index), but how many individuals are needed per sample for diversity analysis is debated. It may be as few as 300 to 500 individuals are adequate per sample, as this would likely include rare species (Magurran 2004 and discussion therein). In the SO deep sea, though, we suggest that a higher number might be needed (Kaiser et al. 2007) due to patchiness (Fig. 4).

\subsection{New approaches}

In some areas the SO has now been sampled at comparable levels to elsewhere, but very uneven in time, geography and bathymetry. Sampling of the deep sea has been patchy in time since the mid-1800s, but most has taken place in just the last 2 decades (see Fig. 5). The density of sampling is strongly linked to the proximity of scientific research stations. Bias by bathymetry is even stronger and has mainly focussed at shelf depths (Table 1). For example, $91.7 \%$ of SO mollusc sample locations are at shelf and just $2.3 \%$ at abyssal depths (Griffiths et al. 2003). The few SO expeditions to collect samples deeper than $1000 \mathrm{~m}$ have been mainly concentrated around the Weddell Sea.

Sample bias and assessment of levels of knowledge are obviously crucial to understanding the deep sea and the responses of biota to projected changes. Even though the deep sea appears poorly sampled, true levels of knowledge are actually much lower than can be measured by sample intensity and timing. For example, few deep SO benthic samples have ever been completely analysed, such that some remain completely unsorted, some sorted only to higher taxonomic levels and some have detailed all individuals of a few model taxa to species level. Even in the latter case, many or most of the species are new and thus wait to be formally described, as for example in one of the more intensively studied taxa, the isopod crustaceans (see Brandt et al. 2007a). It is clear, therefore, that to gain a baseline of knowledge and understanding it will require a great deal more than merely increasing geographic sampling effort. When the biota of existing samples have been identified in terms of taxonomy, functional and ecological roles and the nature of distributions, it will be important to use such information as 'feedback' to improve sampling strategy. One important way to do this is by integrating the findings from use of different types of sampling apparatus to provide a more holistic view of the deep seabed. 


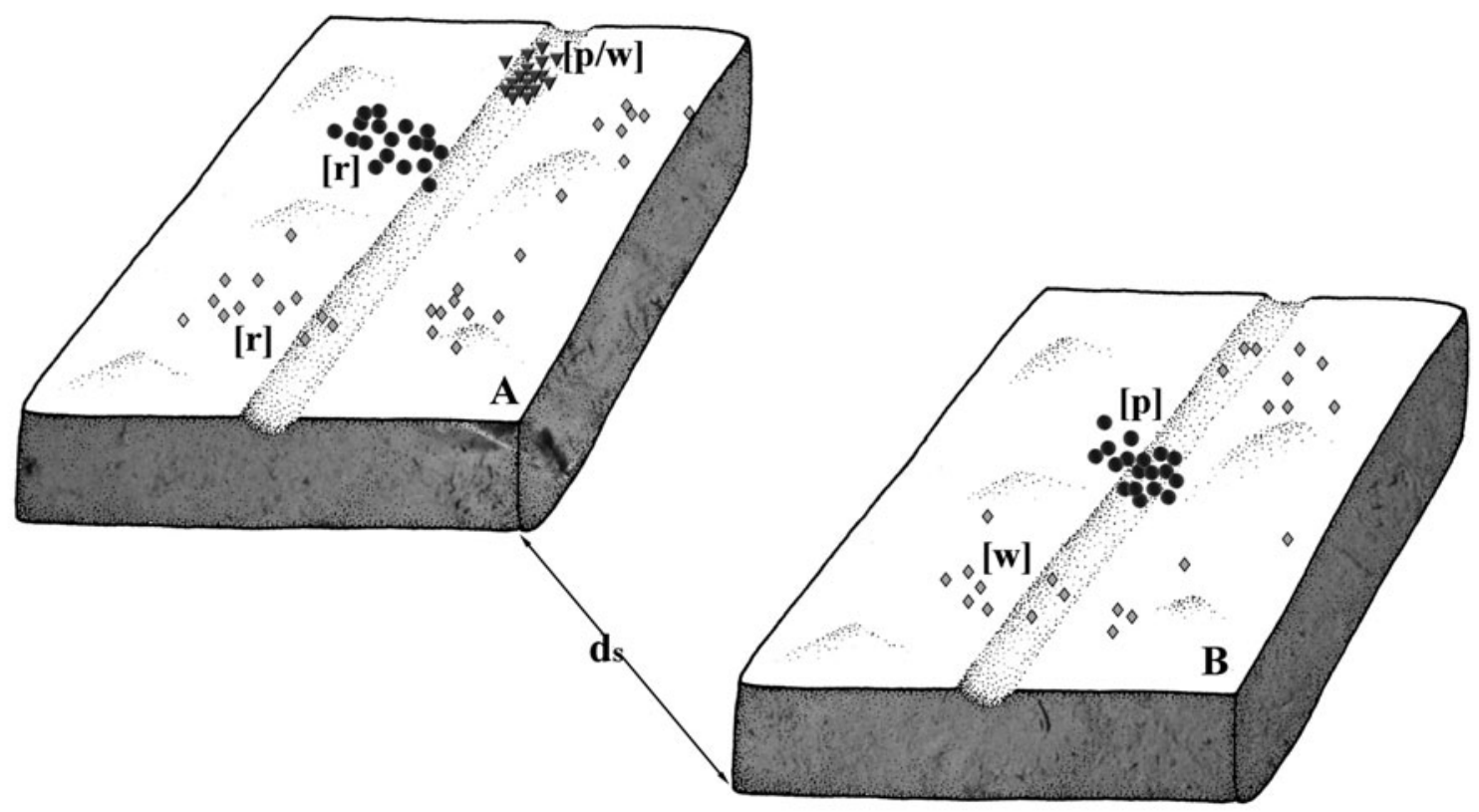

Fig. 4. Schematic showing hypothetical sampling of biota on a deep SO seabed. A trawl (central trough) samples parts of populations, and it is often hard to assess whether a species is patchy or rare from such information. One species (diamond) appears rare (r) in Sample A, but Sample B reveals the species to be widely distributed (w); a second species (circle) appears rare from Sample A, but is revealed to be quite abundant in Sample B. Clearly it is either patchy (p) or widely distributed (depending on the definition of patchiness, the distance between samples [ds] and the number of replicates [sampling size]). A third species (triangle) is very abundant in Sample A, but absent in Sample B. Whether this species is rare or just patchily distributed requires further sampling to determine. Figure background is modified from Brandt et al. (2007a)

As all sampling techniques are biased (but in different ways), it is important to use a complementary set of apparatus that is comparable across expeditions. Ultimately, sampling within an 'area' and across spatial, but also temporal scales, using multiple samples from each apparatus type, should enable comparison of the

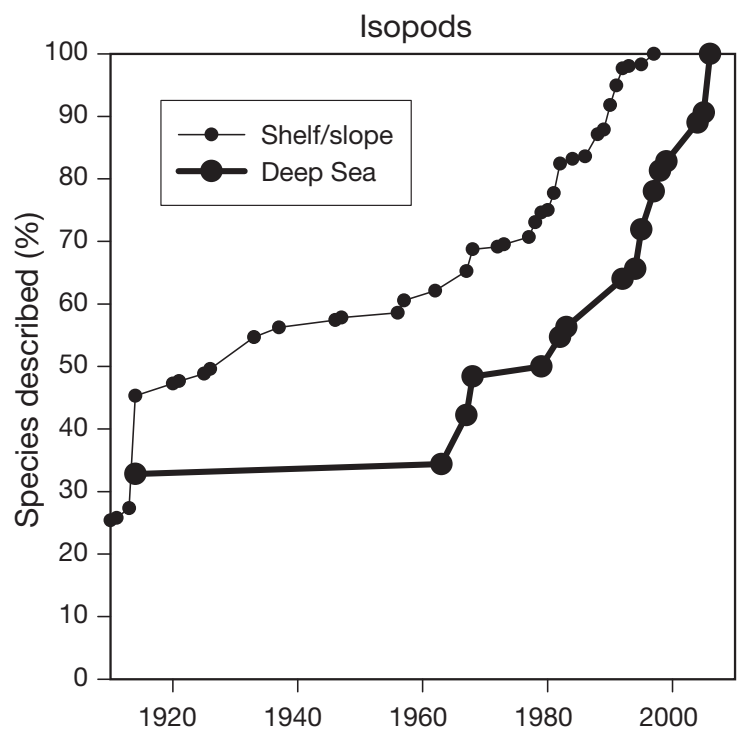

variability within and between samples and methodologies. This would be a major step towards understanding how fauna is organised and which factors influence diversity and distributions (Fig. 4). We are not close to this state of knowledge, for any deep-sea site or for a total inventory of all possible niches

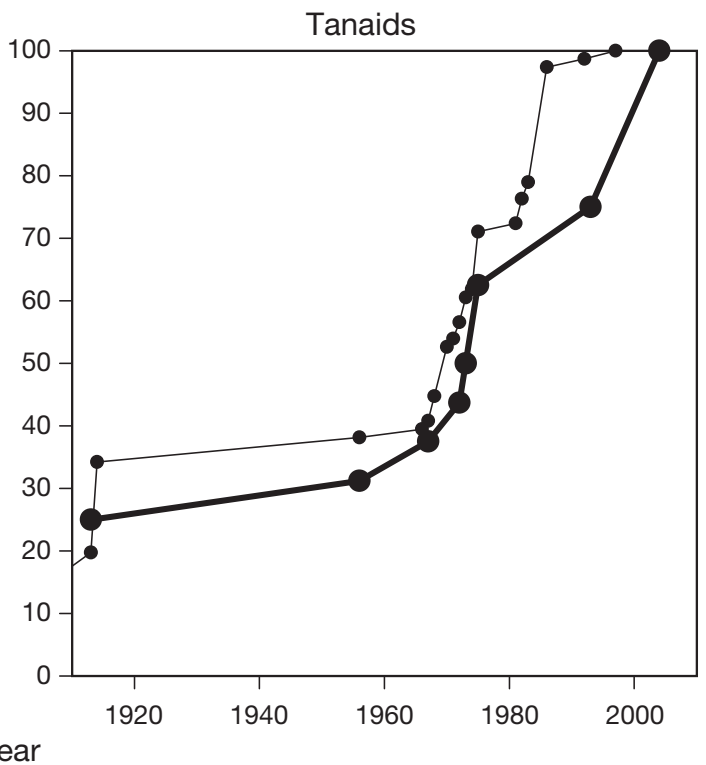

Fig. 5. Rate of new species descriptions in isopod and tanaid crustaceans from the Antarctic shelf versus abyss over the past 120 yr (modified from Clarke \& Johnston 2003). Few species have been described from the deep sea to date, and most of them have been described in the last 4 decades 
(Magurran 2004). Technically, it should be possible to establish monitoring of a deep-sea region, and, given the overlying warming (Meredith \& King 2005), ice retreat (Cook et al. 2005) and level of adjacent shelf knowledge (Clarke \& Johnston 2003), the deep Bellingshausen Sea is perhaps the ideal location.

\section{CONCLUSIONS}

Signals of climate change pervade the world's surface environments and, to date, seem most acute in the Arctic and WAP regions, but are not yet apparent in the global or SO deep sea. There can be little doubt that acidification, warming, de-oxygenation and other changes will occur, but the extent, timing and rate of change is hard to project. As in shallower waters, it seems likely that many such parameters will be very small and physiologically irrelevant to organisms at first, maybe for decades, but will rapidly increase over centuries. However, there is evidence of a number of abrupt switches (e.g. in ocean overturning leading to global temperature changes) in the past and rapid freshening may trigger one of these. Any long lag phase means that abyssal acidification, warming and other related changes may continue intensifying even centuries after any future decrease in $\mathrm{CO}_{2}$ (for example, following fossil fuel exhaustion). A major component of climate change in surface environments is the increasing frequency of brief, but acute events, such as sudden warming, but vast volumes of water above the deep sea buffer any temporary, extreme physical change. However, the relative constancy of the deep sea on ecological time scales has made alterations in sediments an important record of past changes. Its connectivity with the global deep sea and the driving of (for example) oxygenation there makes monitoring of present and future changes vital. Furthermore, the continuity of the SO deep sea with the rapidly altering Antarctic shelf, coupled with the high eurybathy of organisms, could result in faunistic shifts even before any physical changes are detectable. Shelf organisms around the Antarctic have little linear (north to south) coast to migrate along, unlike elsewhere, but they may have greater potential to migrate by submerging. Advances have been made in understanding deep-sea biodiversity and its dynamics, but as much as anything these have revealed how little we know. For instance, species new to science dominate samples. New studies have shown that many, or even most, deep-sea species may be patchily distributed and that both abundance and richness varies as much between samples 10s of kilometres apart as between ocean basins. Quantifying the scale at which patchiness occurs and what drives variability in abundance and richness will provide a big step forward in our understanding. Currently, biologists experiment on how organisms might respond by subjecting them to increases in physical parameters, but, to date, these studies have focussed on rapid and considerable rises, which are not predicted to such extents within the lifetimes of organism in the deep sea. We need to address meaningful elevations and time scales on deep-sea species at ambient pressure.

Acknowledgements. The authors thank Profs A. Clarke, A. Brandt, P. Martinez-Arbizu, and Drs J. Guerrero-Kommritz, K. Linse, M. Schüller, T. Munilla, P. Hayward, S. N. Brandao, J. Strugnell, M. Meredith, H. T. Banks and H. J. Griffiths for providing valuable information. We are grateful to 3 anonymous referees for constructive comments leading to an improved manuscript. We acknowledge a grant to S.K. from the German Science Foundation (DFG, Contract No. Br 1121/ 26-3) and the German Academic Exchange Service (DAAD) for financial support.

\section{LITERATURE CITED}

Adkins JF, Cheng H, Boyle EA, Druffel ERM, Edwards RL (1998) Deep-sea coral evidence for rapid change in ventilation of the deep North Atlantic 15,400 years ago. Science 280:725-728

Anderson RF, Chase Z, Fleisher MQ, Sachs J (2002) The Southern Ocean's biological pump during the Last Glacial Maximum. Deep-Sea Res II 49:1909-1938

Arntz WE, Gutt J, Klages M (1997) Antarctic marine biodiversity: an overview. In: Battaglia B, Valencia J, Walton DWH (eds) Antarctic communities. Species, structure and survival. Cambridge University Press, Cambridge, p 3-14

Barnes DKA, Griffiths HJ (2008) Biodiversity and biogeography of southern temperate and polar bryozoans. Glob Ecol Biogeogr 17:84-99

Barnes DKA, Peck LS (2008) Vulnerability of Antarctic shelf biodiversity to predicted regional warming. Clim Res 37 : 149-163

Barnes DKA, Hodgson DA, Convey P, Allen CS, Clarke A (2006) Incursion and excursion of Antarctic biota: past, present and future. Glob Ecol Biogeogr 15:121-142

Barnes RSK (1998) The diversity of living organisms. Blackwell Science, London

Blake JA, Narayanaswamy BE (2004) Benthic infaunal communities across the Weddell Sea Basin and South Sandwich Slope, Antarctica. Deep-Sea Res II 51:1797-1815

Brandt A, Gooday AJ, Brandao SN, Brix S and others (2007a) First insights into the biodiversity and biogeography of the Southern Ocean deep sea. Nature 447:307-311

> Brandt A, De Broyer C, De Mesel I, Ellingsen KE and others (2007b) The biodiversity of the deep Southern Ocean benthos. Philos Trans R Soc Lond B Biol Sci 362:39-66

Brey T, Dahm C, Gorny M, Klages M, Stiller M, Arntz WE (1996) Do Antarctic benthic invertebrates show an extended level of eurybathy? Antarct Sci 8:3-6

Clarke A (1996) Benthic marine habitats in Antarctica. In: Ross RM, Hoffman EE, Quentin LB (eds) Origins and evolution of the Antarctic biota. Geol Soc Spec Publ 47:253-268

Clarke A (2003) The polar deep sea. In: Tyler PA (ed) The deep seafloor. Ecosystems of the World. Elsevier, Amsterdam, p 239-260

Clarke A, Johnston NM (2003) Antarctic marine benthic 
diversity. Oceanogr Mar Biol Annu Rev 41:47-114

Clarke A, Murphy EJ, Meredith MP, King JC and others (2007) Climate change and the marine ecosystem of the western Antarctic Peninsula. Philos Trans R Soc Lond B Biol Sci 362:149-166

Collins MA, Rodhouse PGK (2006) Southern Ocean cephalopods. Adv Mar Biol 50:191-265

Cook AJ, Fox AJ, Vaughan DG, Ferrigno JG (2005) Retreating glacier fronts on the Antarctic Peninsula over the past half-century. Science 308:541-544

Danovaro R, Dell’Anno A, Pusceddu A (2004) Biodiversity response to climate change in a warm deep sea. Ecol Lett 7:821-828

> Dickson B, Yashayaev I, Meincke J, Turrell B, Dye S, Hoffort J (2002) Rapid freshening of the deep North Atlantic Ocean over the past four decades. Nature 416:832-837

Ellingsen KE (2001) Biodiversity of a continental shelf softsediment macrobenthos community. Mar Ecol Prog Ser 218:1-15

EPICA (European Project for Ice Coring in Antarctica) (2004) Eight glacial cycles from an Antarctic ice core. Nature 429:623-628

Falkowski PG, Katz ME, Milligan A, Fennel K and others (2005) The rise of oxygen over the past 205 million years and the evolution of large placental mammals. Science 309:2202-2204

Francois R, Altabet MA, Yu EF, Sigman DM and others (1997) Contribution of Southern Ocean surface-water stratification to low atmospheric $\mathrm{CO}_{2}$ concentrations during the last glacial period. Nature 389:929-935

Gage JD (1996) Why are there so many species in deep-sea sediments? J Exp Mar Biol Ecol 200:257-286

Gage J (2004) Diversity in deep-sea benthic macrofauna: the importance of local ecology, the larger scale, the history and the Antarctic. Deep-Sea Res II 51:1689-1708

Gille ST (2002) Warming of the Southern Ocean since the 1950s. Science 295:1275-1277

Godfrey JS, Rintoul SR (1998) The role of the oceans in Southern Hemisphere climate. In: Karoly DJ, Vincent DG (eds) Meteorology of the Southern Hemisphere. American Meteorological Society, Boston, p 283-306

Grassle JF, Maciolek NJ (1992) Deep-sea species richness: regional and local diversity estimates from quantitative bottom samples. Am Nat 139:313-341

Gray JS (2001) Marine diversity: the paradigms in patterns of species richness examined. Sci Mar 65(Suppl 2):41-56

> Griffiths HJ, Linse K, Crame AJ (2003) SOMBASE-Southern Ocean mollusc database: a tool for biogeographic analysis in diversity and ecology. Org Div Evol 3:207-213

Gutzmann E, Martinez Arbizu P, Rose A, Veit-Köhler G (2004) Meiofauna communities along an abyssal depth gradient in the Drake Passage. Deep-Sea Res II 51:1617-1628

Hallam A, Wignall PB (1997) Mass extinctions and their aftermath. Oxford Science Publications, Oxford

Hansen J, Sato M, Ruedy R, Lo K, Lea DW, Medina-Elizade M (2006) Global temperature change. Proc Natl Acad Sci USA 103:14288-14293

Hargrave BT (1985) Feeding rates of abyssal scavenging amphipods (Eurythenes gryllus) determined in situ by time-lapse photography. Deep-Sea Res 32:443-450

Harrison K (1988) Seasonal reproduction in deep-sea Crustacea (Isopoda: Asellota). J Nat Hist 22:175-197

Hayward PJ (1981) The Cheilostomata (Bryozoa) of the deep sea. Galathea Rep 15:21-68

Hilbig B, Gerdes D, Montiel A (2006) Distribution patterns and biodiversity in polychaete communities of the Weddell Sea and Antarctic Peninsula area (Southern Ocean).
J Mar Biol Assoc UK 86:711-725

> Hoppema M (2004) Weddell Sea is a globally significant contributor to deep-sea sequestration of natural carbon dioxide. Deep-Sea Res I 51:1169-1177

> Howe JA, Shimmield TM, Diaz R (2004) Deep-water sedimentary environments of the northwestern Weddell Sea and South Sandwich Islands, Antarctica. Deep-Sea Res II 51:1489-1514

Jacobs SS (2004) Bottom water production and its links with the thermohaline circulation. Antarct Sci 16:427-437

Jacobs SS, Giulivi CF, Mele PA (2002) Freshening of the Ross Sea during the late 20th century. Science 297:386-389

Jumars PA (1978) Spatial autocorrelation with RUM (Remote Underwater Manipulator): vertical and horizontal structure of a bathyal benthic community. Deep-Sea Res 25: 589-604

Kaiser S, Barnes DKA, Brandt A (2007) Slope and deep-sea abundance across multiple scales: Southern Ocean isopods show how complex the deep sea can be. Deep-Sea Res II 54:1776-1789

Kennett JP, Stott LD (1991) Abrupt deep-sea warming, palaeoceanographic changes and benthic extinctions at the end of the Palaeocene. Nature 353:225-229

Kim SJ, Crowley TJ, Stössel A (1998) Local orbital forcing of Antarctic climate change during the last interglacial. Science 280:728-730

Lear CH, Elderfield H, Wilson PA (2000) Cenozoic deep-sea temperatures and global ice volumes from $\mathrm{Mg} / \mathrm{Ca}$ in benthic foraminiferal calcite. Science 287:269-272

- Levin SA (1992) The problem of pattern and scale in ecology. Ecology 73:1943-1967

- Levin LA (2002) Deep-ocean life where oxygen is scarce. Am Sci 90:436-444

> Levin LA, Etter RJ, Rex MA, Gooday AJ and others (2001) Environmental influences on regional deep-sea species diversity. Annu Rev Ecol Syst 32:51-93

- Lewis PN, Hewitt CL, Riddle M, McMinn A (2003) Marine introductions in the Southern Ocean: an unrecognised hazard to biodiversity. Mar Pollut Bull 46:213-223

Linse K, Griffiths HJ, Barnes DKA, Clarke A (2006) Biodiversity and biogeography of Antarctic and sub-Antarctic Mollusca. Deep-Sea Res II 53:985-1008

Magurran AE (2004) Measuring biological diversity. Blackwell Publishing, Oxford

> Malyutina M (2004) Russian deep-sea investigations of Antarctic fauna. Deep-Sea Res II 51:1551-1570

- May RM (1988) How many species are there on earth? Science 241:1441-1449

> Meredith MP, King JC (2005) Climate change in the ocean to the west of the Antarctic Peninsula during the second half of the 20th century. Geophys Res Lett 32:L19604

Moore JK, Abbott MR, Richman JG (1999) Location and dynamics of the Antarctic Polar Front from satellite sea surface temperature data. J Geophys Res 104:3059-3073

Munilla T (2008) Check-list of the pycnogonids from Antarctic and subAntarctic waters. Zoogeographic implications. Antarct Sci (in press)

Ninnemann US, Charles CD (2002) Changes in the mode of Southern Ocean circulation over the last glacial cycle revealed by forminiferal stable isotopic variability. Earth Planet Sci Lett (201):383-396

> Orr JC, Fabry VJ, Aumont O, Bopp L and others (2005) Anthropogenic ocean acidification over the twenty-first century and its impact on calcifying organisms. Nature 437:681-686

> Peck LS (2005) Prospects for surviving climate change in Antarctic aquatic species. Front Zool 2:9 
Petit JR, Jouzel J, Raynaud D, Barkov NI and others (1999) Climate and atmospheric history of the past 420,000 years from the Vostok ice core, Antarctica. Nature 399:429-436

Piepenburg D, Gutt J (2006) Bodenfauna arktischer und antarktischer Schelfmeere. In: Lozán JL (ed) Warnsignale aus den Polarregionen: wissenschaftliche Fakten. Büro 'Wiss. Auswertungen', Hamburg, p 126-132

Rahmstorf S (2000) The thermohaline circulation: a system with dangerous thresholds. Clim Change 46:247-256

Raupach M, Wägele JW (2006) Distinguishing cryptic species in Antarctic Asellota (Crustacea: Isopoda) - a preliminary study of mitochondrial DNA in Acanthaspidia drygalskii. Antarct Sci 18:191-198

Raupach M, Held C, Wägele JW (2004) Multiple colonization of the deep sea by the Asellota (Crustacea: Peracarida: Isopoda). Deep-Sea Res II 51:1787-1796

Raupach MR, Marland G, Ciais P, Le Quéré C and others (2007) Global and regional drivers of accelerating $\mathrm{CO}_{2}$ emissions. Proc Natl Acad Sci 104:10288-10293

Richardson G, Wadley MR, Heywood KJ, Stevens DP, Helene Banks HT (2005) Short-term climate response to a freshwater pulse in the Southern Ocean. Geophys Res Lett 32: L03S03

Rogers AD, Clarke A, Peck LS (1998) Population genetics of the Antarctic heteronemertean Parbolasia corrugatus from the South Orkney Islands. Mar Biol 131:1-13

Schotte M, Kensley BF, Shilling S (1995) World list of marine, freshwater and terrestrial Crustacea Isopoda. National Museum of Natural History Smithsonian Institution, Washington, DC. Available at: www.nmnh.si.edu/iz/isopod/

Schüller M, Ebbe B (2007) Global distributional patterns of selected deep-sea Polychaeta (Annelida) from the Southern Ocean. Deep-Sea Res II 54:1737-1751

Schwabe E, Bohn JM, Engl W, Linse K, Schroedl M (2007) Rich and rare-first insights into species diversity and abundance of Antarctic abyssal Gastropoda (Mollusca). Deep-Sea Res II 54:1831-1847

Smedsrud LH (2005) Warming of the deep water in the Weddell Sea along the Greenwich meridian: 1977-2001.

Submitted: October 1, 2007; Accepted: December 21, 2007
Deep-Sea Res I 52:241-258

Smith JE, Risk MJ, Schwarcz HP, McConnaughey TA (1997) Rapid climate change in the North Atlantic during the Younger Dryas recorded by deep-sea corals. Nature 386: 818-820

Thistle D, Sedlacek L, Carman KR, Fleeger JW, Brewer PG, Barry JP (2007) Exposure to carbon dioxide-rich seawater is stressful for some deep-sea species: an in situ, behavioural study. Mar Ecol Prog Ser 340:9-16

Thrush SF, Warwick RM (1997) The ecology of soft-bottom habitats: matching spatial patterns with dynamic processes. J Exp Mar Biol Ecol 216 (Special volume)

Turner J, Colwell SR, Marshall GJ, Lachlan-Cope TA and others (2005) Antarctic climate change during the last 50 years. Int J Climatol 25:279-294

> Vanhove S, Vermeeren H, Vanreusel A (2004) Meiofauna towards the deep South Sandwich Trench (750-6300 m). Deep-Sea Res II 51:1665-1687

Vanreusel A, Vincx M (2003) Nematoda of the world, an interactive database. Available at: http://nemys.ugent.be/ index.asp

Walter T, Palm H, Piepiorka S, Rückert S (2002) Parasites of the Antarctic rattail Macrourus whitsoni (Regan, 1913) (Macrouridae, Gadiformes). Polar Biol 25:633-640

Walther GR, Post E, Convey P, Menzel A and others (2002) Ecological responses to recent climate change. Nature 416:389-395

Watson AJ, Naveira Garabato AC (2006) The role of Southern Ocean mixing and upwelling in glacial-interglacial atmospheric $\mathrm{CO}_{2}$ change. Tellus 58B:73-87

Zachos J, Pagani M, Sloan L, Thomas E, Billups K (2001) Trends, rhythms and aberrations in global climate $65 \mathrm{Ma}$ to present. Science 292:686-693

Zachos JC, Roehl U, Schellenberg SA, Sluijs A and others (2005) Rapid acidification of the ocean during the Palaeocene-Eocene thermal maximum. Science 308:1611-1615

Zwally HJ, Comiso JC, Parkinson CL, Cavalieri DJ, Gloersen P (2002) Variability of Antarctic sea ice 1979-1998. J Geophys Res 107:C5,341

Proofs received from author(s): August 15, 2008 